\title{
Transcription factor cAMP response element modulator (Crem) restrains Pdgf-dependent proliferation of vascular smooth muscle cells in mice
}

\author{
M. D. Seidl • A. K. Steingräber • C. T. Wolf • T. M. H. Sur • \\ I. Hildebrandt • A. Witten • M. Stoll • J. W. Fischer • \\ W. Schmitz $\cdot$ F. U. Müller
}

Received: 15 May 2014 / Revised: 10 November 2014 / Accepted: 10 November 2014 /Published online: 27 November 2014

(C) The Author(s) 2014. This article is published with open access at Springerlink.com

\begin{abstract}
Transcription factors of the cAMP response element-binding protein (Creb)/cAMP response element modulator (Crem) family were linked to the switch from a contractile to a proliferating phenotype in vascular smooth muscle cells (VSMCs). Here, we analyzed the vascular function of Crem in mice with a global inactivation of Crem $\left(\mathrm{Crem}^{-/}\right)$. CRE-mediated transcriptional activity was enhanced in primary $\mathrm{Crem}^{-/}$VSMCs under nonstimulated conditions and under stimulation with Forskolin and platelet-derived growth factor (Pdgf) whereas stimulation with nitric oxide or cGMP showed no effect. This elevated CRE-mediated transcriptional activity as a result of Crem inactivation did not alter aortic contractility or fractions of proliferating or apoptotic aortic VSMCs in situ, and no impact of Crem inactivation on the development of atherosclerotic plaques was observed. $\mathrm{Crem}^{-1}$ - mice exhibited an increased neointima formation after carotid ligation associated with an increased proliferation of VSMCs in the carotid media. Pdgf-stimulated proliferation of primary aortic $\mathrm{Crem}^{-/}$VSMCs was increased along with
\end{abstract}

M. D. Seidl and A. K. Steingräber contributed equally to this work.

Electronic supplementary material The online version of this article (doi:10.1007/s00424-014-1652-6) contains supplementary material, which is available to authorized users.

M. D. Seidl $(\varangle) \cdot$ A. K. Steingräber • C. T. Wolf • T. M. H. Sur • I. Hildebrandt $\cdot$ W. Schmitz $\cdot$ F. U. Müller

Institute for Pharmacology and Toxicology, University of Münster, Domagkstr. 12, D-48149 Münster, Germany

e-mail: seidl@uni-muenster.de

\section{A. Witten $\cdot$ M. Stoll}

Institute for Human Genetics, Genetic Epidemiology, University of Münster, D-48129 Münster, Germany

J. W. Fischer Institute for Pharmacology and Clinical Pharmacology, Düsseldorf University Hospital, D-40225 Düsseldorf, Germany an upregulation of messenger RNA (mRNA) levels of Pdgf receptor, alpha polypeptide (Pdgfra), cyclophilin A (Ppia), the regulator of G-protein signaling 5 (Rgs 5 ), and Rho GTPase-activating protein 12 (Arhgap12). Taken together, our data reveal the inhibition of Pdgf-stimulated proliferation of VSMCs by repressing the Pdgf-stimulated CRE-mediated transcriptional activation as the predominant function of Crem in mouse vasculature suggesting an important role of Crem in vasculoproliferative diseases.

Keywords Vascular tone $\cdot$ Neointima $\cdot$ Proliferation $\cdot$ Crem . CRE-mediated transcription

\section{Introduction}

cAMP response element-binding protein ( $\mathrm{Creb})$ and cAMP response element modulator (Crem) are structurally related transcription factors regulating the transcription of multiple genes in response to cAMP, cGMP, and other second messengers $[33,32]$. Both transcription factors exhibit a notable functional diversity through the existence of splice variants and the formation of homodimers or heterodimers binding to the cAMP response element (CRE; TGACGTCA and variants thereof) in the promoter regions of their target genes [17, 25]. The phosphorylation of Creb at Ser-133 by the cAMPdependent protein kinase A (PKA) represents an important mechanism of CRE-mediated transcriptional activation. In contrast, a number of Crem variants, particularly small isoforms including inducible cAMP early repressor (Icer) and small Icer (smIcer), suppress CRE-mediated transcriptional activation $[38,26,7]$. These repressors contain the DNAbinding domain enabling them to bind to the CRE; however, they lack functional domains responsible for transactivation or the inducibility by kinases [26]. 
Cyclic AMP promotes quiescence and maintenance in vascular smooth muscle cells (VSMCs) and the $\beta$ adrenoceptor, and cAMP-dependent activation of PKA is important to sustain their contractile function under normal conditions [35]. Creb is an important downstream target of PKA, and changes in Creb phosphorylation or function are correlated with the regulation of cell proliferation [18, 41], apoptosis [42], migration [15, 29], VSMC hypertrophy [8], or vascular resistance [23]. Elevated cAMP levels inhibit platelet-derived growth factor (Pdgf)-stimulated VSMC growth by PKA/Creb-dependent induction of transformation-related protein 53 (p53) and cyclin-dependent kinase inhibitor 1A (p21) and by inhibition of mitogenactivated protein kinase (MAPK) signaling [2, 11]. Several studies showed the relevance of Creb for the regulation of vascular quiescence and the development of vasculoproliferative diseases $[35,14]$. Schauer et al. reported that downregulation of Creb is a common pathological response to vascular injury and seems to contribute to plaque progression [37]. It is suggested that most Crem isoforms (including Icer and smIcer) act as repressors of CREdependent gene transcription. Therefore, Crem might play an important role as a counterpart of $\mathrm{Creb}$ in the vasculature.

Aldosterone-induced impaired vascular contractility reportedly goes along with diminished glucose- 6 phosphate dehydrogenase expression due to increased Crem levels [22], and a transient overexpression of Icer inhibited neointima formation in balloon-injured rat carotid artery [28]. However, the physiological role of Crem in the intact vascular system is fragmentary and has not yet been systematically studied in knockout models.

In order to elucidate the general role of Crem in the vasculature, we investigated the CRE-mediated transcriptional activation in response to important stimuli in the vasculature, namely nitric oxide (NO), cAMP, cGMP, and Pdgf in Crem knockout mice $\left(\mathrm{Crem}^{-/-}\right)$and wild-type $\left(\mathrm{Crem}^{+/+}\right)$controls. Since Pdgf and cAMP stimulation increased CRE-mediated gene expression in $\mathrm{Crem}^{-/}$vs. $\mathrm{Crem}^{+/+}$VSMCs, we investigated the relevance of enhanced CRE-mediated transcription by $\mathrm{Crem}$ inactivation under physiological and pathological conditions in the vasculature. In particular, the impact of Crem inactivation on vascular contractility, plaque development after high-fat diet, and neointima formation after vascular injury by carotid ligation was assessed. Moreover, we analyzed apoptosis and proliferation rates of aortic VSMCs and identified possible target genes of Crem relevant in this context.

\section{Material and methods}

For detailed description of cell culture; transient transfection; histological, histochemical, and immunofluorescence imaging; and quantitative real-time PCR, see the expanded material and methods part in the online supplement.

Experimental animals and materials The generation of Crem mutant mice lacking the DNA-binding domains of the Crem gene was published previously [3]. We thank Dr. G. Schütz, DKFZ Heidelberg, Germany, for providing $\mathrm{Crem}^{-/-}$mice. $\mathrm{Crem}^{-/-}$and $\mathrm{Crem}^{+/+}$mice originated from the same mouse colony which has been continued for more than ten generations on the same mixed background (129Sv:C57/Bl6). All animal experimentation was performed in accordance with local animal welfare authorities and approved by the LANUV-Regional Authority for Nature, Environment and Consumer protection in North Rhine-Westphalia, Germany (permit number: 8.8751.04.20.09.386 or 84.02.04.2011.A179). Surgery was performed under isoflurane-nitrous oxide anesthesia, and every effort was made to minimize suffering. All chemicals were purchased from Sigma (Sigma-Aldrich Chemie GmbH, Steinheim, Germany) as not stated otherwise.

Analysis of aortic reactivity Aortic vascular tone was measured in male $\mathrm{Crem}^{-/-}$and $\mathrm{Crem}^{+/+}$mice of $17-18$ weeks. Preparation and initial treatment of thoracic aortae as well as mounting to the dual-wire myograph system (model 410A; J.P. Trading, Aarhus, Denmark) were described before [19]. After $45 \mathrm{~min}$ of equilibration in a $10-\mathrm{ml}$ bath of physiologic salt solution (in mmol/l, $118 \mathrm{NaCl}, 25$ $\mathrm{NaHCO}_{3}, 2.5 \mathrm{CaCl}_{2}, 4.7 \mathrm{KCl}, 1.2 \mathrm{KH}_{2} \mathrm{PO}_{4}, 1.2 \mathrm{MgSO}_{4}$, 5.5 glucose, and 0.026 ethylene diamine tetraacetate) at $37{ }^{\circ} \mathrm{C}$, aortic rings were stretched to a passive resting tension of $17.5 \mathrm{mN}$, followed by several constrictions induced by a high-potassium solution (K-PSS) composed of (in mmol/l) the following: $25 \mathrm{NaHCO}_{3}, 2.5 \mathrm{CaCl}_{2}$, $122.7 \mathrm{KCl}, 1.2 \mathrm{KH}_{2} \mathrm{PO}_{4}, 1.2 \mathrm{MgSO}_{4}, 5.5$ glucose, and 0.026 ethylene diamine tetraacetate. Vasoconstriction was measured after stimulation with the $\alpha$-adrenoceptor agonist phenylephrine (PE) or prostaglandin $\mathrm{F}_{2 \alpha}$. Vasorelaxation was studied after precontraction with $1 \mu \mathrm{mol} / 1 \mathrm{PE}$ and stimulation with the m-cholinoceptor agonist carbachol, the $\beta$-adrenoceptor agonist isoproterenol, or with the nitrogen oxide donor sodium nitroprusside. Vasoconstrictions and relaxations (Fig. 3a, c-e) were determined as first effects after $\mathrm{K}^{+}$contractions except prostaglandin $\mathrm{F}_{2 \alpha}$ $\left(\mathrm{PGF}_{2 \alpha}\right.$, second effect after PE contraction experiments) followed by an injection of $1 \mu \mathrm{mol} / \mathrm{l}$ carbachol to test endothelial response (exclusion criterion less than $70 \%$ relaxation). PE-induced vasoconstriction and precontractions for carbachol and sodium nitroprusside were performed in the presence of $1 \mu \mathrm{mol} / \mathrm{l}$ propranolol to exclude possible $\beta$-adrenergic effects of PE. For the separate endothelium-denuded experiments, the 
endothelium was removed by carefully rubbing a wire on the inner side of the aortic rings. The successful endothelium denudation was checked by the relaxation response before and after denudation by $10^{-6} \mathrm{M}$ acetylcholine stimulation after norepinephrine $\left(10^{-6} \mathrm{M}\right)$ contraction. All drugs were directly added to the bath. For treatment of mice with isoprenaline, osmotic mini-pumps (model 2001, Alzet, Cupertino, USA) were implanted in mice for continuous application of $10 \mathrm{mg} / \mathrm{kg}$ body weight/day of isoprenaline (DL-isoprenaline hydrochloride) for 7 days according to the manufacturer's instructions.

Mouse carotid ligation model and sham operation Carotid artery ligation model was performed with male $\mathrm{Crem}^{-/-}$ and $\mathrm{Crem}^{+/+}$mice as a modification of the model published by Kumar et al. [20, 21]. Mice were anesthetized by intraperitoneal injection of avertin solution (tribromoethanol $0.36 \mathrm{mg} / \mathrm{g}$ body weight with 2methyl-2-butanol $0.18 \mathrm{mg} / \mathrm{g}$ body weight). A midline neck incision was made to expose the left and right common carotid arteries. Sham operation was performed on the left artery as a contralateral control, before the right carotid artery was ligated by a 5-0 propylene suture proximal to the carotid bifurcation. After 3 weeks of recovery, mice were sacrificed and the carotid arteries were excised and fixated overnight in neutral buffered formaldehyde (4\%). Tissues were dehydrated and embedded in paraffin as described above. Series of eight 5 - $\mu \mathrm{m}$ sections were prepared on glass slides of the right and left arteries. For the right ligated arteries, carotid sections in a proximal distance to ligation of 0,200 , 400, 700, and $1000 \mu \mathrm{m}$ were collected and stained for morphometric evaluation with resorcin-fuchsin and nuclear fast red. For the sham-ligated left carotid arteries, morphometric values were obtained from three different slides and calculated as a mean for each vessel. For immunohistochemical analysis, sections of the right carotid artery were investigated in a proximal distance to ligation of $0-200 \mu \mathrm{m}$.

Statistics If not stated otherwise, data are expressed as mean values \pm standard error of the mean (SEM) with $n$ indicating the number of independent experiments. In cell culture experiments, the number of independent transfections and the number of separate cells isolations are indicated. For statistical evaluation, two-way ANOVA and Tukey post hoc tests were used to compare multiple groups. For comparison of two groups, Student's $t$ test was conducted. Statistical differences were considered as significant at $p<0.05$. All statistical analyses were performed using SigmaPlot (version 11.2; Systat Software, Erkrath, Germany) except the statistical analysis of RT-PCR results and calculation of relative expression ratios which were conducted by the relative expression software tool (RESTC) Version 2.07) [30, 44].

\section{Results}

Increased CRE-dependent transcriptional activity in VSMCs from $\mathrm{Crem}^{-1}$ mice after stimulation with cAMP or Pdgf At first, we tested the effect of Crem inactivation on CREmediated transcriptional activation in isolated primary aortic VSMCs. Staining of these cells revealed a proportion $>95 \%$ of the smooth muscle marker smooth muscle myosin heavy chain (Myh11), while the marker of endothelial cells Von Willebrand factor (Vwf) was detectable in less than $4 \%$ of the cells (Fig. 1a-e). CRE-dependent transcriptional activity was measured after transient transfection of VSMCs with a CRE-controlled reporter gene plasmid and subsequent stimulation with activators of the cAMP- (Forskolin, a direct receptor-independent activator of the adenylyl cyclase) or cGMP-dependent (8-pCPT-cGMP and $S$-nitroso- $N$ acetylpenicillamine (SNAP)) signaling cascades or in response to the growth factor Pdgf. Cells were stimulated with different concentrations of Forskolin $\left(3 \times 10^{-8}-3 \times 10^{-5} \mathrm{~mol} / \mathrm{l}\right)$, or DMSO (1 mmol/l) as solvent control. (Fig. 1f). Forskolin increased the CRE-controlled promoter activity in a concentration-dependent manner in both groups. However, Crem inactivation led to an enhanced induction of CREcontrolled transcriptional activity after stimulation with $3 \times$ $10^{-6}$ to $3 \times 10^{-5} \mathrm{~mol} / 1$ Forskolin; nonstimulated VSMCs of $\mathrm{Crem}^{-/-}$mice showed a significant 1.5 -fold increase in the CRE-controlled transcriptional activity (Fig. $1 \mathrm{~g} ; p<0.05$ ). Hence, the inactivation of Crem in $\mathrm{Crem}^{-/-}$mice was associated with an increased CRE-dependent transcriptional activity both in response to Forskolin and under basal conditions in aortic VSMCs. Stimulation with the cGMP analogon 8-pCPTcGMP (9 h; $\left.10^{-4} \mathrm{M}\right)$ or with the NO donator SNAP (9 h; $\left.10^{-4} \mathrm{M}\right)$ did not reveal an increase in CRE-mediated transcriptional activity versus nonstimulated control conditions in both genotypes (Fig. 1h, i). Stimulation with the growth factor Pdgf $(9 \mathrm{~h} ; 7.5 \mathrm{ng} / \mathrm{ml})$ exclusively increased the CRE-mediated gene expression in $\mathrm{Crem}^{-/}$VSMCs while Pdgf had no effect in $\mathrm{Crem}^{+/+}$cells, indicating that Crem can completely block the impact of Pdgf on CRE-dependent gene expression (Fig. 1j).

No morphological differences and an unaltered rate of apoptotic or proliferating aortic VSMCs in the aorta of $\mathrm{Crem}^{-/}$ mice The increased CRE-mediated transcriptional activation, in particular under basal, nonstimulated conditions (Fig $1 \mathrm{~g}$ ) in $\mathrm{Crem}^{-1-}$ mice raised the question whether inactivation of Crem is associated with functional alterations in the mouse vasculature. However, histological analysis of aortae from 

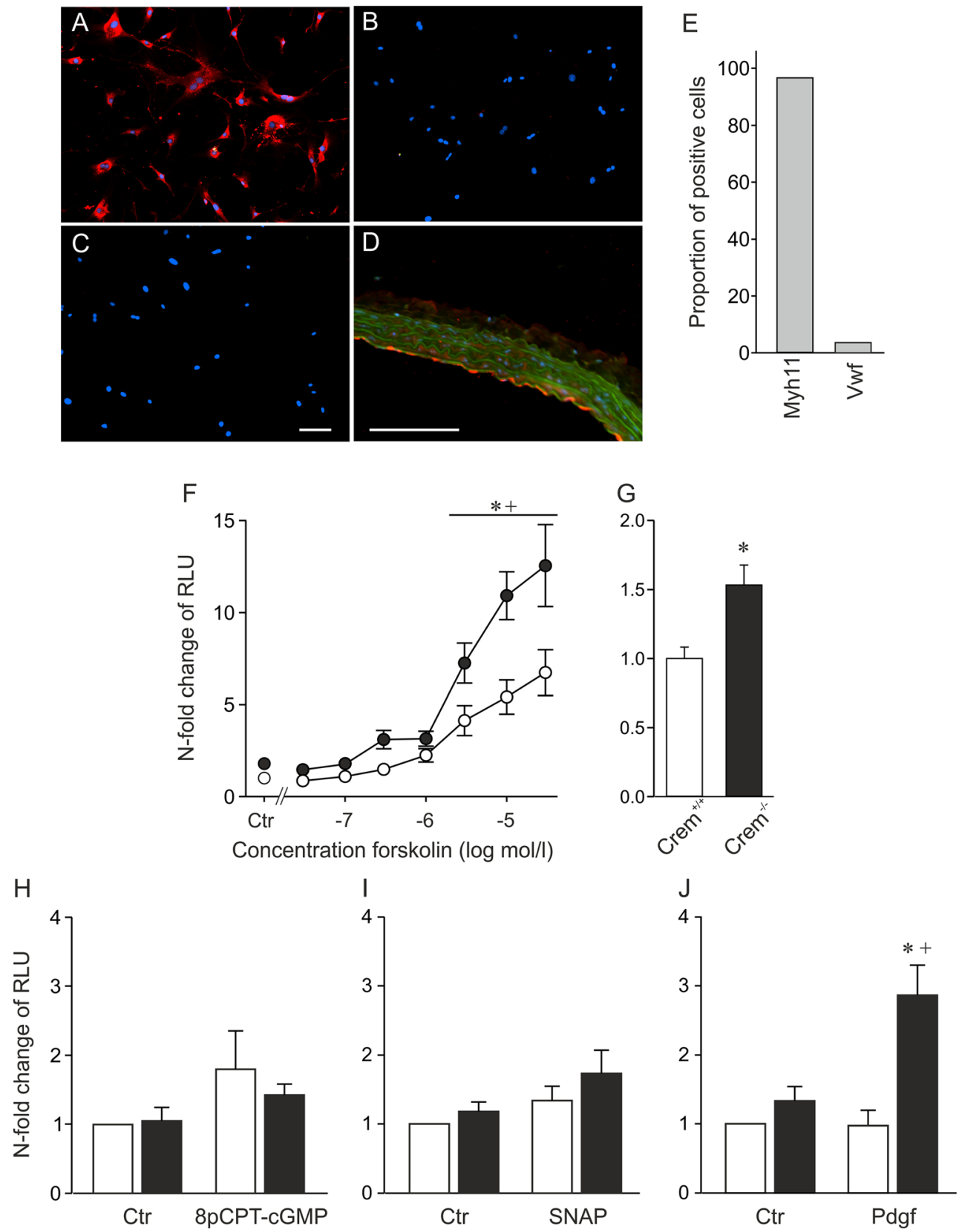

Fig. 1 Characterization of VSMC culture by immunofluorescence staining (a-e). Photographs of isolated VSMCs incubated with an antibody against the a smooth muscle myosin heavy chain (Myh11), b Von Willebrand factor (Vwf), $\mathbf{c}$ the secondary antibody control without primary antibody, and $\mathbf{d}$ positive control of the Vwf antibody in aortic sections; note the positive red staining of the endothelium. e Quantification of the proportion of stained cells based on 350 analyzed cells revealed over $95 \%$ positive staining of the cells by the VSMC marker Myh11; scale bar $100 \mu \mathrm{m}$. f-j CRE-mediated transcriptional activation of isolated VSMCs from $\mathrm{Crem}^{+/+}$(white symbols) and $\mathrm{Crem}^{-1-}$ (black symbols) mice. VSMCs were transiently transfected with a CRE-controlled luciferase reporter gene construct and treated with

activators of different signaling cascades or solvent controls $(C t r)$. $\mathbf{f}$ Forskolin (in DMSO, $n=8 / 6$ meaning eight independent transfections from six isolations, for $12 \mathrm{~h}$; Ctr: $n=15-18 / 6), \mathbf{h ~} 10^{-4} \mathrm{M} 8$-pCPTcGMP (in $\mathrm{H}_{2} \mathrm{O}, n=6 / 6$, for $9 \mathrm{~h}$ ), $\mathbf{i} 10^{-4} \mathrm{M}$ SNAP (in $\mathrm{H}_{2} \mathrm{O}, n=7 / 7$, for $9 \mathrm{~h}$ ), and $\mathbf{j} 7.5 \mathrm{ng} / \mathrm{ml} \operatorname{Pdgf}$ (in $\mathrm{H}_{2} \mathrm{O}, n=5 / 5$, for $9 \mathrm{~h}$ ). Data were presented relative to the mean of $\mathrm{Crem}^{+/+} \mathrm{Ctr}$, which was set to 1 . Note the elevated CRE-dependent transcriptional activity under stimulation with $3 \times 10^{-8}$ $3 \times 10^{-5} \mathrm{M}$ Forskolin (f) and Pdgf (j) in VSMCs of $\mathrm{Crem}^{-1-}$ mice. Independent analysis of untreated transfected VSMCs (g) revealed a 1.5 -fold increase in VSMCs from $\mathrm{Crem}^{-/-}$vs. $\mathrm{Crem}^{+/+}$mice $(n=51-54 /$ 3). Asterisk $(*)$ denotes $p<0.05$ vs. $\mathrm{Crem}^{+/+}$, a cross $(+)$denotes $p<0.05$ vs. control

$\mathrm{Crem}^{-1-}$ mice did not show any differences in comparison to $\mathrm{Crem}^{+/+}$mice. There was no change in the thickness of the media $\left(\mathrm{Crem}^{+/+}, 53 \pm 1 \mu \mathrm{M}, n=3\right.$; $\left.\mathrm{Crem}^{-/-}, 54 \pm 4 \mu \mathrm{M}, n=3\right)$.
In order to assess possible effects of Crem inactivation on important functions of aortic smooth muscle cells, we studied the impact of Crem inactivation on the fraction of apoptotic 
and proliferating aortic VSMCs. There were no significant differences between $\mathrm{Crem}^{-/-}$and $\mathrm{Crem}^{+/+}$mice regarding both the basal proliferation rate and the proportion of apoptotic cells of VSMCs (Fig. 2).
Unaltered regulation of aortic vascular tone in $\mathrm{Crem}^{-}$ mice Vascular tone was studied in aortic rings from $\mathrm{Crem}^{-1-}$ and $\mathrm{Crem}^{+/+}$mice in a wired myograph system. Concentration-dependent vasoconstriction was measured

\section{Endogene}

DAPI
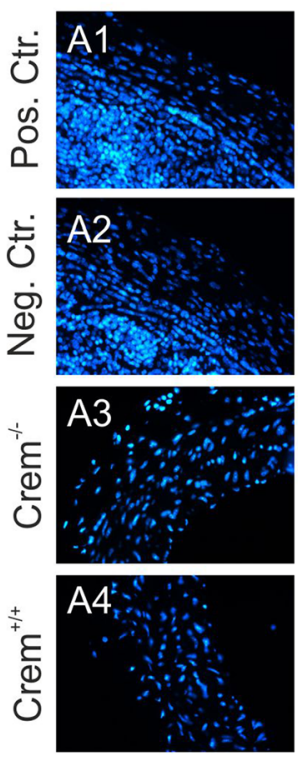

DAPI
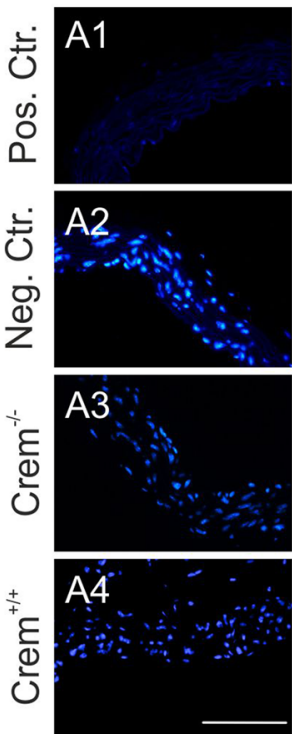

Ki-67
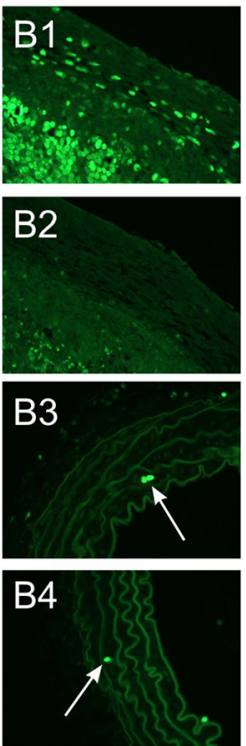

TUNEL
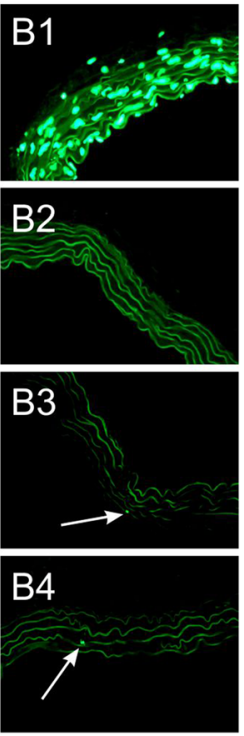
fluorescence

Overlay
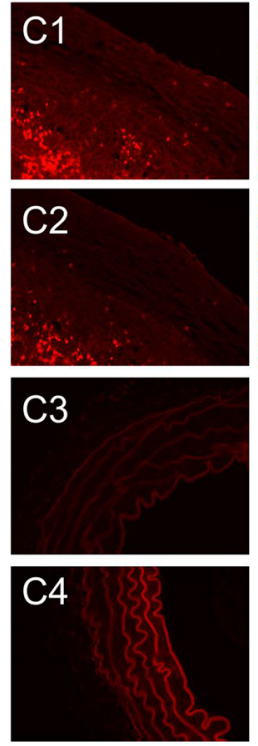

Ab-SM $\alpha$-actin
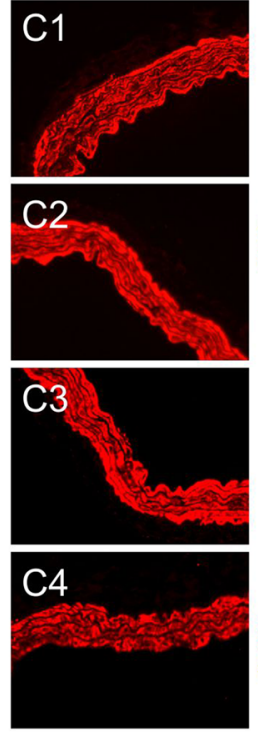

Overlay
Fig. 2 Detection of proliferating VSMCs (top) in aortic sections from $\mathrm{Crem}^{-/-}$and $\mathrm{Crem}^{+/+}$mice (A3-D3 and $\left.A 4-D 4\right)$. Photomicrographs show the following: DAPI cell nuclei staining $(A 1-4)$, proliferating VSMCs detected by a Ki-67 antibody (B1-4; white arrows), the endogenous fluorescence $(C 1-4)$, and the overlay $(D 1-4)$. As a positive control, spleen tissue sections with a high proliferation rate were stained with the Ki-67 antibody $(A 1-D 1)$ and were incubated as a negative control without the first Ki-67 antibody (A2-D2) (bottom). Detection of apoptotic VSMCs in aortic sections from $\mathrm{Crem}^{+/+}$and $\mathrm{Crem}^{-/}$mice $(A 3-D 3$ and $A 4-D 4)$. Photomicrographs show the following: the cell nuclei stained
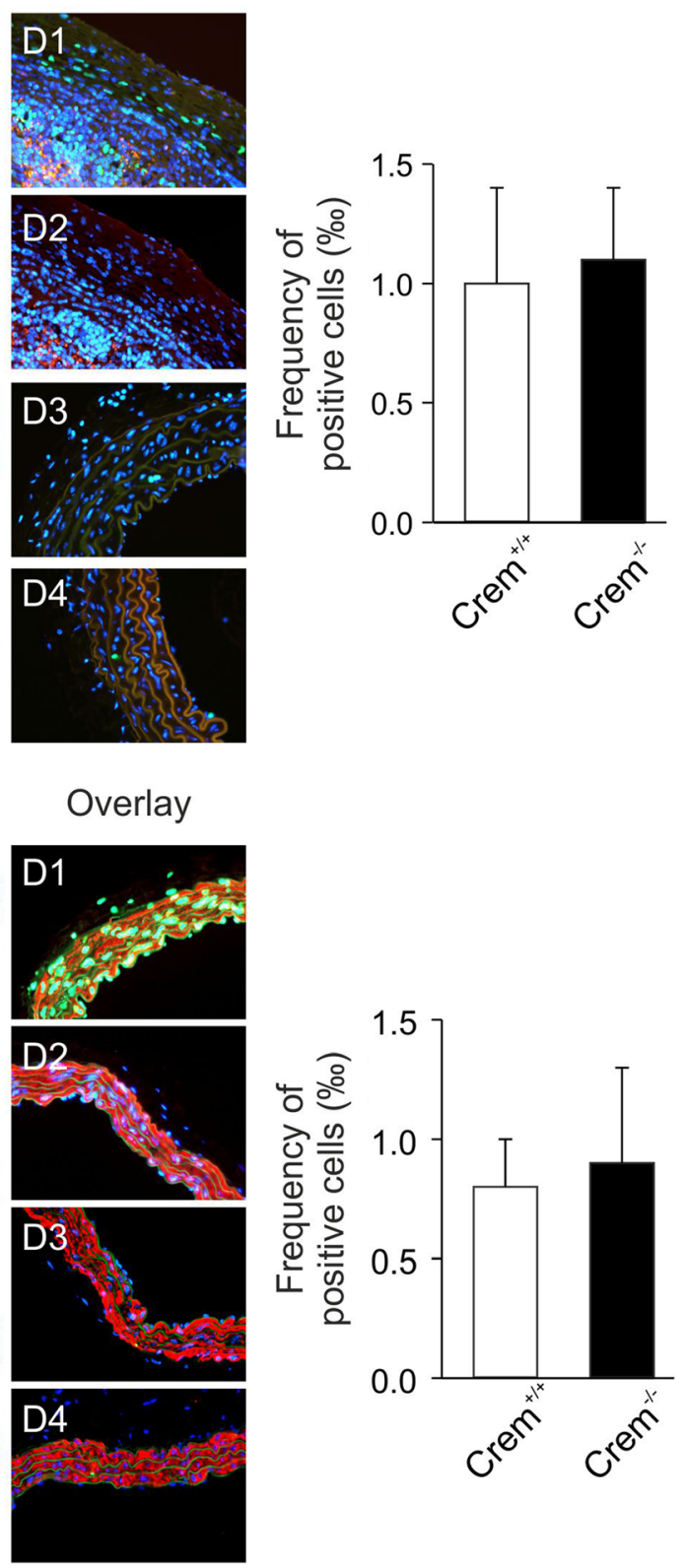

with DAPI (A1-4), the apoptotic VSMCs detected by a TUNEL assay (B1-4; white arrows), VSMCs visualized by a smooth muscle actinspecific antibody $(C 1-4)$, and the overlay $(D 1-4)$. As a positive control, aortic sections were treated with DNase I $(A 1-D 1)$, and as a negative control, sections were treated without enzyme $(A 2-D 2)$. Statistical analysis of the frequency of apoptotic cells in the aortic sections of $\mathrm{Crem}^{+/+}$ (white) and $\mathrm{Crem}^{--}$(black) mice revealed no significant differences in the fraction of proliferating or apoptotic VSMCs in the aorta (right); $n=3$ based on $5960 \pm 550$ cells for detection of proliferating cells and $6030 \pm$ 220 cells for detection of apoptotic cells in each group, respectively 
under stimulation with the $\alpha_{1}$-adrenoceptor agonist phenylephrine (PE, Fig. 3a) or with prostaglandin $\mathrm{F}_{2 \alpha}\left(\mathrm{PGF}_{2 \mathrm{a}}\right.$, Fig. 3b). Vasodilatation was studied after precontraction with $1 \mu \mathrm{mol} / 1$ $\mathrm{PE}$ and application of increasing concentrations of the $\beta$ adrenoceptor agonist isoproterenol (ISO, Fig. 3c). NOdependent vasodilatation was measured under stimulation with both the endothelium-dependent NO-releasing mcholinoceptor agonist carbachol (CAR, Fig. 3d) or the endothelium-independent $\mathrm{NO}$ donor sodium nitroprusside (SNP, Fig. 3e). Overall, there were no significant differences between groups, neither in maximum or in minimum wall tension of contraction or relaxation nor in the half maximal effective concentration $\left(\mathrm{EC}_{50}\right)$ /half maximal inhibitory concentration $\left(\mathrm{IC}_{50}\right)$ values (see supplemental Fig. S1). To exclude endothelium-dependent effects, aortic contractility was also studied in denuded aortae after PE, ISO, CAR, and SNP stimulation (Fig. 3f-i). Moreover, contractility was measured after 7 days of isoproterenol administration in intact and denudated aortae (Fig. 3j-m). Denudation showed a marked impact on aortic contractility. PE showed a higher potency reflected by a left shift of the dose-response curve. The relaxation after ISO or CAR treatment was markedly impaired after
Fig. 3 Cumulative drug-induced contractions and relaxations in wall tension of aortic rings (a-e), relative wall tensions after denudation (triangles) compared to intact aortae (circle) without (f-i) and with 1 week of chronic isoproterenol treatment $(\mathbf{j}-\mathbf{m})$ in $\mathrm{Crem}^{+/+}$(open symbols) and $\mathrm{Crem}^{-/-}$(filled symbols) male mice. Curves in dark gray $(\mathbf{j}-\mathbf{m})$ show data of untreated aortae (fi). The vascular tone was measured in response to stimulation with the $\alpha$-adrenoceptor agonist phenylephrine (a, $\mathbf{f}, \mathbf{j} ; P E, n=4-6)$ and prostaglandin $\mathrm{F}_{2 \alpha}\left(\mathbf{b} ; P G F_{2 \alpha}\right.$, $\left.\mathrm{Crem}^{+/+} n=4, \mathrm{Crem}^{-/-} n=3\right)$. Relaxations were induced after preconstriction with PE $(1 \mu \mathrm{mol} /$ 1) by the $\beta$-adrenoceptor agonist isoproterenol (c, $\mathbf{g}, \mathbf{k} ; I S O ; n=4$ 6), the muscarinic receptor agonist carbachol (d, h, l; CAR; $n=5$ 8 ), and the nitric oxide donor sodium nitroprusside (e, i, m; $S N P$; $n=4-9$ ). No significant differences between $\mathrm{Crem}^{+/+}$and $\mathrm{Crem}^{-/-}$mice were observed
A

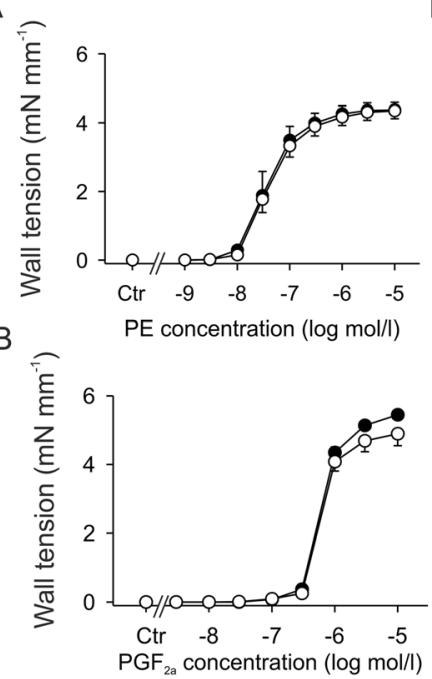

$\mathrm{C}$

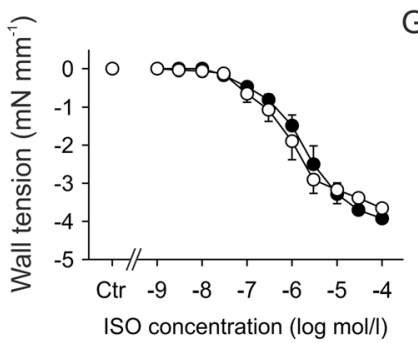

D

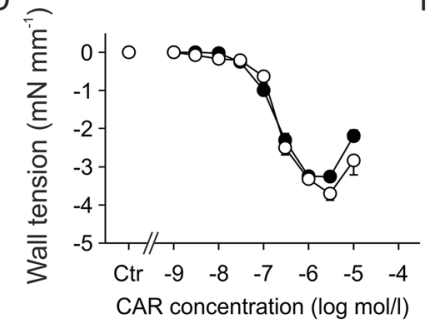

E

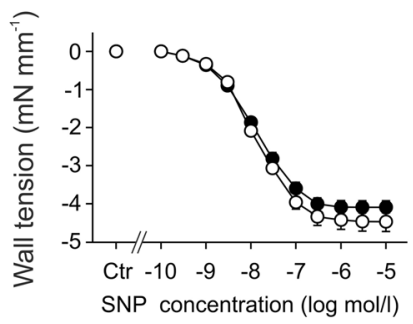

$\mathrm{H}$

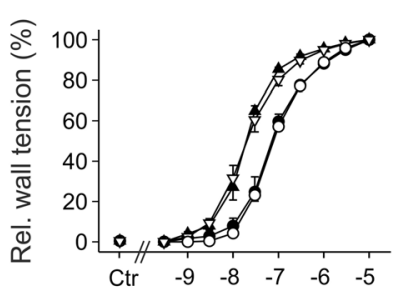

$\mathrm{PE}$ concentration (log $\mathrm{mol} / \mathrm{l})$

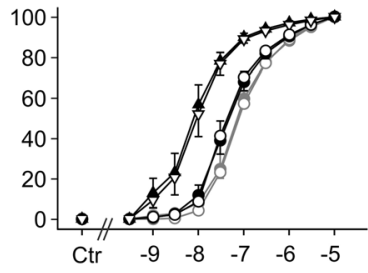

PE concentration (log $\mathrm{mol} / \mathrm{l})$

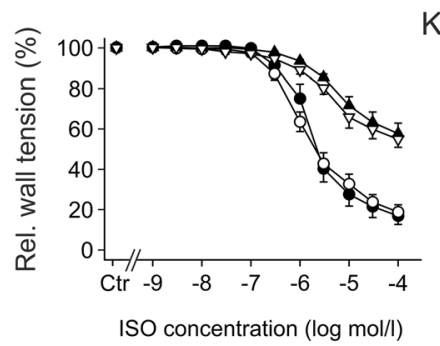

K
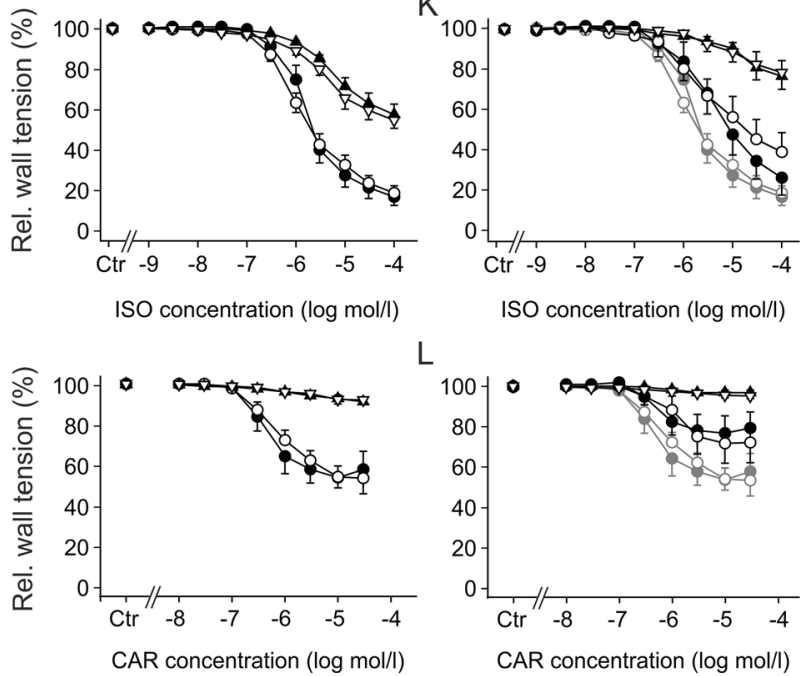

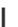

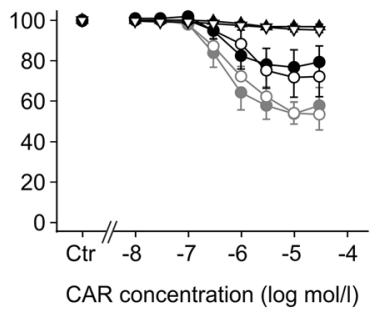

$\mathrm{M}$

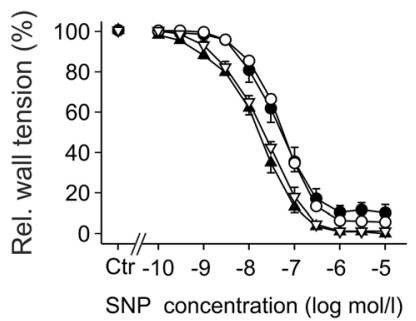

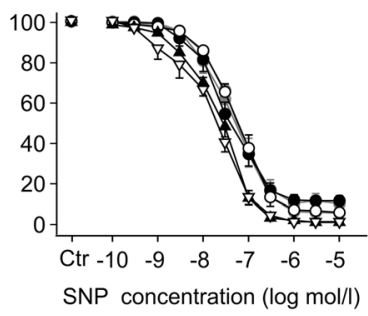


Fig. 4 Analysis of neointima formation of the right carotid artery 3 weeks after ligation. a Resorcinfuchsine and nuclear fast red staining of the cross sections of the ligated right and sham-operated left carotid artery from $\mathrm{Crem}^{+/+}$and $\mathrm{Crem}^{-/-}$mice. b Downregulation of relative Crem mRNA levels in $\mathrm{Crem}^{+/+}$sham $(n=6)$ and ligated carotids $(n=4)$. Quantification of neointima $(\mathbf{c})$ and media area $(\mathbf{d})$ in $\mathrm{Crem}^{+/+}$(white, $\left.n=10\right)$ and $\mathrm{Crem}^{-}$ mice (black, $n=9)$. Note the severe increase in neointima formation in the $\mathrm{Crem}^{-/}$mice. e Icam1and Vcam1-specific immunofluorescent staining of carotid cross sections of ligated carotids from $\mathrm{Crem}^{+/+}$and $\mathrm{Crem}^{-/-}$mice. Quantification of Icam1- (f) and Vcam1 (g)-stained area showed no differences between the genotypes. ${ }^{*} p<0.05$ vs. $\mathrm{Crem}^{+/+}$(post hoc tests, two-way ANOVA). h Detection of proliferating VSMCs in the cross sections of ligated carotids. Photomicrographs show the following: the cell nuclei stained with DAPI, proliferating cells (VSMCs) detected by a Ki-67 antibody (white arrows), visualization of VSMCs with a smooth muscle actin-specific antibody, and the overlay. $\mathrm{Crem}^{-/-}$VSMCs showed an increase in the percentage of proliferating VSMCs in the media but not in the neointima (for details, see text). Scale bars= $100 \mu \mathrm{m}$
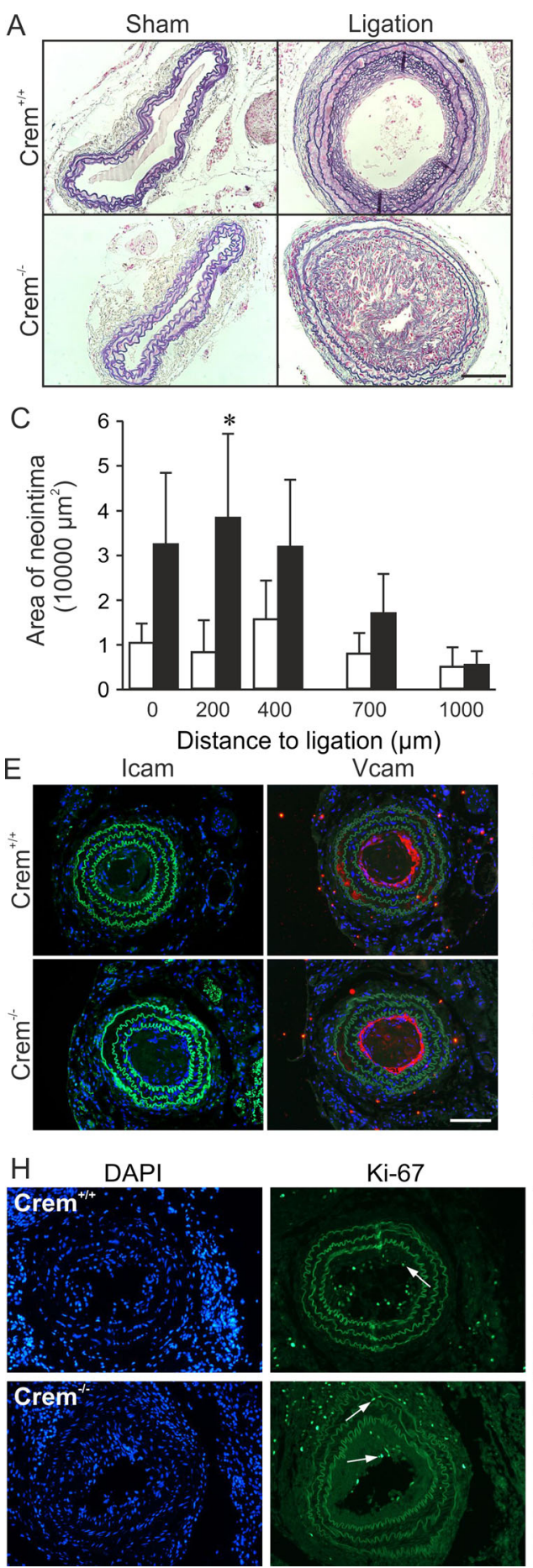

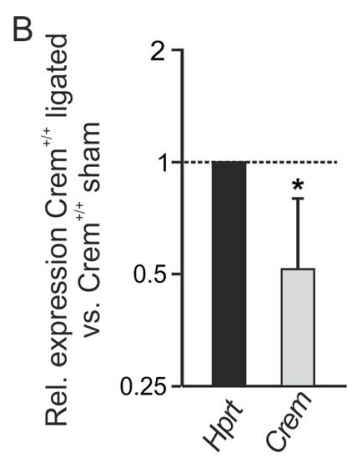

D
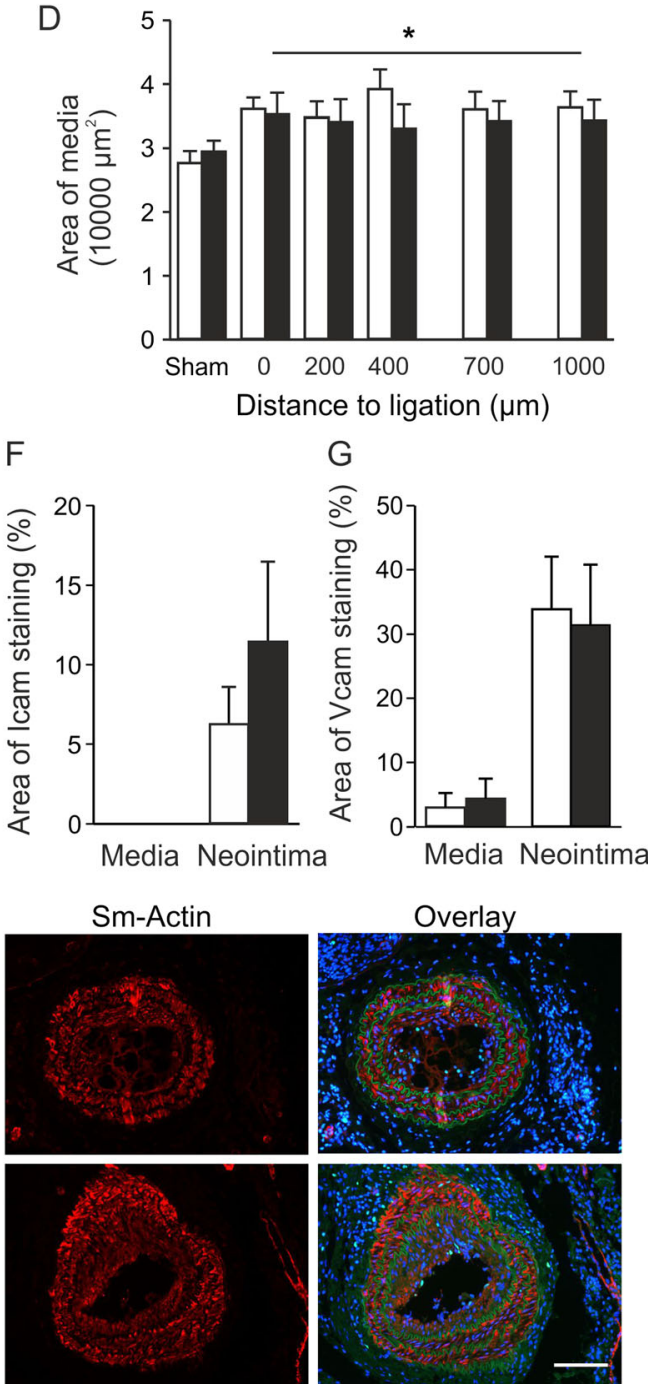

denudation, while SNP treatment showed a slight increase in efficiency and potency. Isoproterenol treatment showed a similar but less pronounced effect on PE, ISO, and CAR doseresponse curves which could be superimposed by denudation, while the chronic isoproterenol treatment had no effect on the SNP-stimulated relaxation. However, both denudation of aortic rings as well as isoproterenol treatment and their combination showed no difference between $\mathrm{Crem}^{-/-}$and $\mathrm{Crem}^{+/+}$mice.
Unaltered plaque development in $\mathrm{Crem}^{-/} \times \mathrm{ApoE}^{-/-}$ mice After analysis of basal morphological and physiological functions, we investigated the impact of Crem inactivation in atherosclerotic plaque development in aortae on an $A p o E$ knockout $\left(\mathrm{ApoE}^{-/}\right.$) background and in a model of vascular injury by carotid ligation. Red oil $\mathrm{O}$ staining of aortae revealed no difference in plaque area in $\mathrm{Crem}^{-/} \times \mathrm{ApoE}^{-/-}$compared to $\mathrm{Crem}^{+/+} \times \mathrm{ApoE}^{-/-}$mice after 20 weeks of high-fat diet, 


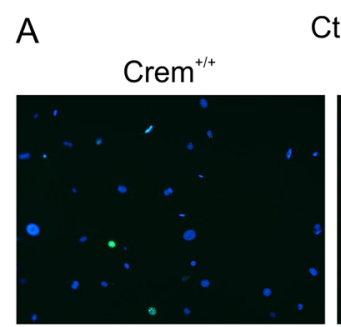

Ctr

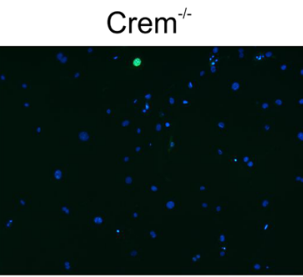

$\mathrm{B}$
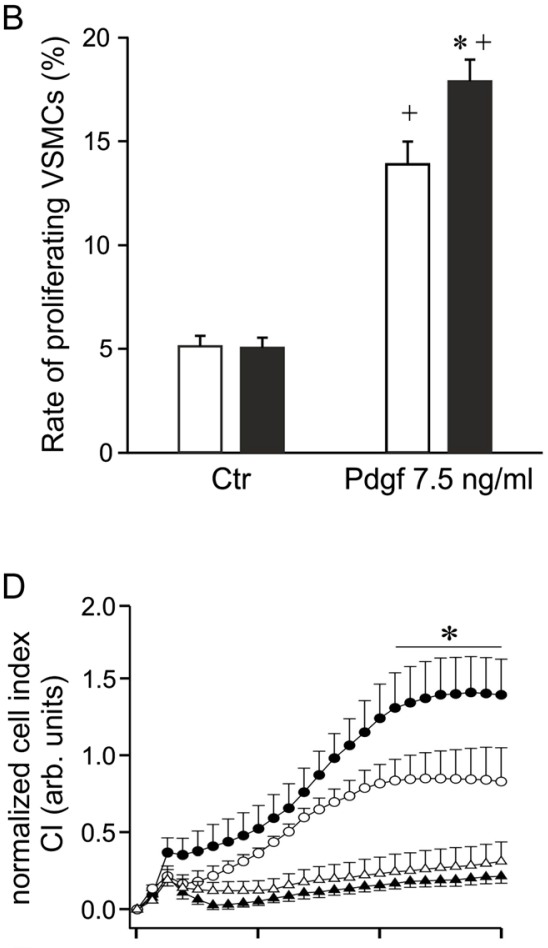

E

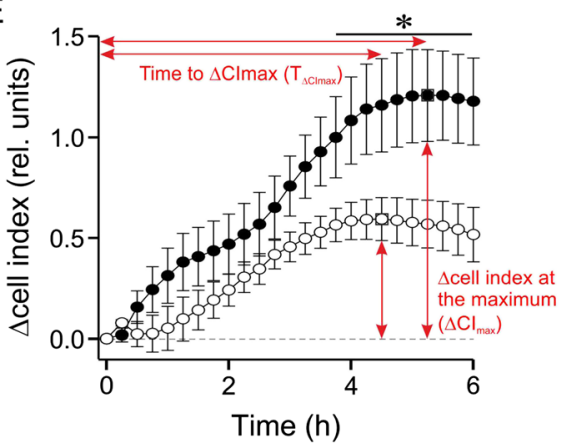

Fig. 5 Detection of proliferating and apoptotic cells in primary isolated VSMCs from $\mathrm{Crem}^{+/+}$(white bars) and $\mathrm{Crem}^{-/-}$(black bars) mice. a Immunofluorescence images of VSMCs stained with DAPI and a Ki-67 antibody to detect proliferating cells after stimulation with Pdgf $(7.5 \mathrm{ng} / \mathrm{ml}, 24 \mathrm{~h})$ compared to control conditions without stimulation (Ctr). b Quantitative analysis showed an increase in the percentage of proliferating VSMCs in $\mathrm{Crem}^{-/-}$vs. $\mathrm{Crem}^{+/+}$VSMCs in the Pdgf-treated groups $(n=14 / 5)$. c Percentage frequency of apoptotic VSMCs was detected by TUNEL assay after 24-h stimulation with increasing concentrations of hydrogen peroxide. No differences between the genotypes were observed $(n=10 / 6)$. d Impedance-based real-time proliferation curves of vehicle-treated (triangle) and Pdgf $(7.5 \mathrm{ng} / \mathrm{ml})$-treated VSMCs

while a slight $7 \%$ increase after 30 weeks of high-fat diet was observed. The control groups showed small red oil O-positive
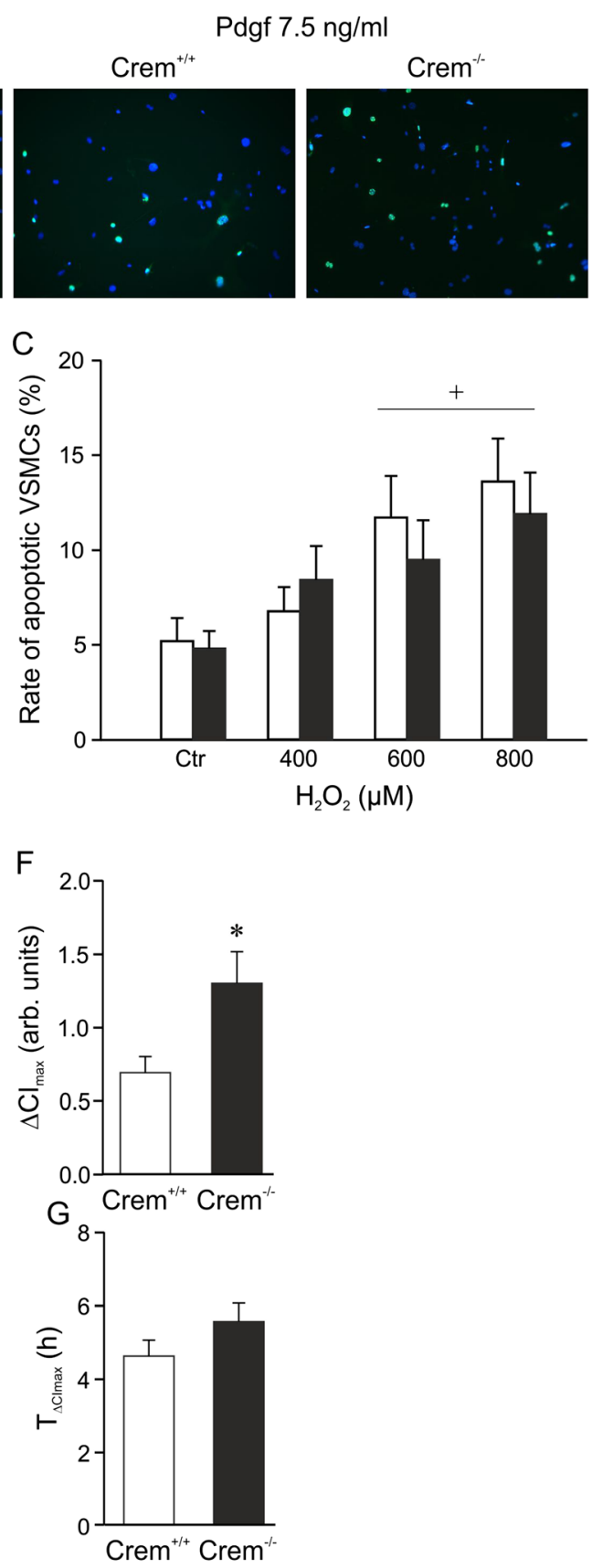

(circle) of $\mathrm{Crem}^{-/-}(n=8 ;$ black $)$ and $\mathrm{Crem}^{+/+}$VSMCs $(n=8 ;$ white $)$ normalized to the time point before Pdgf treatment (e). The differential proliferation curves of Pdgf-treated minus Pdgf-untreated VSMCs and the calculation of the $\mathbf{f}$ maximum cell index $\left(\Delta C I_{\max } ;\right.$ square $)$ and the $\mathbf{g}$ time to the maximum $\left(T_{\Delta \text { CImax }}\right)$ are shown (all $\left.n=8\right)$. Note the increased proliferation rate in Pdgf-stimulated $\mathrm{Crem}^{-/-}$compared to $\mathrm{Crem}^{+/+}$ VSMCs, represented by the increased cell index of proliferation curves and the higher $\Delta \mathrm{CI}_{\max }$ values, while the time to $\Delta \mathrm{CI}_{\max }$ was not changed. Asterisk $(*)$ denotes $p<0.05$ vs. $\mathrm{Crem}^{+/+}$, and the cross $(+)$denotes $p<0.05$ vs. control conditions. For statistical analysis of proliferation curves, a two-way repeated measures ANOVA and Tukey post hoc tests were used

areas with no differences between genotypes after 30 weeks of standard diet (supplemental Fig. S2A, B). A detailed analysis 
of the root of the aortic arch showed no difference in the main plaque area and the area-positive macrophage staining (supplemental Fig. S2C, D). Moreover, no differences were found in the proliferation rate of VSMCs in the media $\left(\mathrm{Crem}^{+/+} \times\right.$ $\mathrm{ApoE}^{-/-} 0.48 \pm 0.17$ vs. $\mathrm{Crem}^{-/-} \times \mathrm{ApoE}^{-/-} 0.32 \pm 0.17 \%$ VSMCs) and in the proliferation rate of all cell types in the plaques $\left(\mathrm{Crem}^{+/+} \times \mathrm{ApoE}^{-/-} 4.1 \pm 0.5\right.$ vs. $\mathrm{Crem}^{-/-} \times \mathrm{ApoE}^{-/-}$ $3.7 \pm 0.8 \%$ VSMCs; see supplemental Fig. S2F). Analysis of cell content showed a comparable cell density in the media $\left(\mathrm{Crem}^{+/+} \times \mathrm{ApoE}^{-/-} 3844 \pm 453\right.$ vs. $\mathrm{Crem}^{-/-} \times \mathrm{ApoE}^{-/-} 3120 \pm$ 228 cells $\left./ \mathrm{mm}^{2}\right)$ and the plaques $\left(\mathrm{Crem}^{+/+} \times \mathrm{ApoE}^{-/-} 3190 \pm\right.$ 244 vs. $\mathrm{Crem}^{-/} \times \mathrm{ApoE}^{-/} 3331 \pm 389$ cells $/ \mathrm{mm}^{2}$ ) between the genotypes. Measurement of triglycerides, high- and lowdensity lipoprotein (HDL and LDL, respectively) and cholesterol revealed no differences between the genotypes (see supplemental Fig. S3). Overall inactivation of Crem had a minor impact on the progression of plaque development.

Increased neointima formation after ligation of carotids in $\mathrm{Crem}^{-/}$mice $\mathrm{Crem}^{-/-}$mice showed a severe increase in neointima formation (Fig. 4a, c) when compared to $\mathrm{Crem}^{+/+}$ mice, while elevation of media thickness compared to the sham controls remained equal between the genotypes (Fig. 4d). Quantification of relative Crem messenger RNA (mRNA) levels revealed a $48 \%$ decrease in sham versus ligated WT carotids (Fig. 4b). Furthermore, no difference in the expression of intercellular adhesion molecule 1 (Icam1) and vascular cell adhesion molecule 1 (Vcam1) was observed between genotypes (Fig. 4d-f). The increased neointima formation in $\mathrm{Crem}^{-/}$mice was accompanied by a significant increase of proliferating VSMCs in the media $\left(\mathrm{Crem}^{+/+} 0.11 \pm\right.$ 0.06 vs. $\mathrm{Crem}^{-/-} 0.79 \pm 0.26 \%$ VSMCs) but not in the neointima $\left(\mathrm{Crem}^{+/+} 4.5 \pm 2.5\right.$ vs. $\mathrm{Crem}^{-/-} 1.9 \pm 0.7 \%$ VSMCs; see Fig. 4g). Separate analysis of cell content showed a comparable cell density in the media $\left(\mathrm{Crem}^{+/+} 4451 \pm 259\right.$ vs. $\mathrm{Crem}^{-/-}$ $4931 \pm 195$ cells $\left./ \mathrm{mm}^{2}\right)$ and the neointima $\left(\mathrm{Crem}^{+/+} 6374 \pm 488\right.$ vs. $\mathrm{Crem}^{-/-} 6648 \pm 1484$ cells $/ \mathrm{mm}^{2}$ ) between genotypes.

Increased fraction of proliferating primary VSMCs but unaltered fraction of apoptotic VSMCs in $\mathrm{Crem}^{-/}$mice Since an elevated proliferation rate of VSMCs was observed in the ligated carotids, we studied effects of Crem inactivation in primary VSMCs both under basal conditions and under stimulation of proliferation with Pdgf. There was no difference in the proliferation under nonstimulated control conditions. Stimulation with Pdgf $(7.5 \mathrm{ng} / \mathrm{ml})$ for $24 \mathrm{~h}$ increased the number of proliferating cells in both genotypes (Fig. 5a, b). Under this condition, the proportion of proliferating cells was 1.3-fold higher in $\mathrm{Crem}^{-/-}$vs. $\mathrm{Crem}^{+/+}$VSMCs. Furthermore, we studied the rate of apoptotic VSMCs under basal conditions and after triggering apoptosis with $\mathrm{H}_{2} \mathrm{O}_{2} \cdot \mathrm{H}_{2} \mathrm{O}_{2}$ significantly increased the rate of TUNEL-positive cells in a concentration-dependent manner in both groups (Fig. 5c).
However, there were no differences between genotypes. To substantiate the finding of increased VSMC proliferation rate in $\mathrm{Crem}^{-/}$mice, we measured cell growth in an impedancebased Real-Time Cell Analyzer (RCTA). Again, cell growth of $\mathrm{Crem}^{-/}$VSMCs was elevated compared to $\mathrm{Crem}^{+/+}$under stimulation with Pdgf, while proliferation rate under basal condition was unaltered (Fig. 5d). This was also represented by the differential proliferation curves of Pdgf-treated and Pdgf-untreated cells (Fig. 5e) and the 2-fold higher maximum cell index $(\mathrm{CI})$, while the time point of the maximum CI was not altered (Fig. 5f, g).

To identify genes which are differentially regulated between the Pdgf-stimulated VSMCs of $\mathrm{Crem}^{-/-}$and $\mathrm{Crem}^{+/+}$ mice, a microarray analysis was performed (data not shown). Verification of putative-regulated genes by quantitative real-time PCR analysis (Table $1, n=5$ ) revealed an upregulation of Rho GTPase-activating protein 12 (Arhgap 12), cyclophilin A (Ppia), the regulator of Gprotein signaling $5(R g s 5)$, and the Pdgf receptor, alpha polypeptide (Pdgfra) mRNA in Pdgf-stimulated VSMCs from $\mathrm{Crem}^{-/-}$vs. $\mathrm{Crem}^{+/+}$mice. Other genes which tended to be upregulated comprise the fibroblast growth factor 18 ( Fgfl 18 , angiotensin II, type I receptor-associated protein (Agtrap), and TAF12 RNA polymerase II, TATA boxbinding protein (TBP)-associated factor (Taf12).

Rgs5 mRNA levels were also upregulated in untreated aortae of $\mathrm{Crem}^{-/-}$compared to $\mathrm{Crem}^{+/+}$mice, while the mRNA levels of the other genes were unaltered (Table 2, $n=11-12$ ).

\section{Discussion}

In this study, we systematically analyzed the relevance of the cAMP-mediated transcription factor Crem in the vasculature under physiological and pathophysiological conditions. Main results of the functional inactivation of Crem comprise the following: (i) an increased CRE-mediated transcriptional activation under basal conditions and in response to stimulation with Forskolin and Pdgf in isolated primary VSMCs. (ii) The enhanced CRE-mediated transcription was not associated which a major impact in the following: the physiology of aortic VSMCs under basal conditions, aortic contractility, and plaque development after high-fat diet. (iii) Contrary to this inconspicuous phenotype, a severe increase of neointima development after carotid ligation was observed, which was accompanied by an elevated proliferation rate of VSMCs in the media. (iv) In accordance to this finding, an increased amount of proliferating VSMCs under stimulation with Pdgf in isolated VSMCs was observed. Hence, we showed that as a predominant function in VSMCs, Crem represses the Pdgfactivated CRE-mediated gene transcription, which is 
Table 1 Expression analysis of selected genes in VSMCs of $\mathrm{Crem}^{-/}$ and $\mathrm{Crem}^{+/+}$mice stimulated with $7.5 \mathrm{ng} / \mathrm{ml}$ Pdgf-BB by quantitative real-time PCR

\begin{tabular}{llll}
\hline Gene & Relative expression & Standard error & $p$ value \\
\hline Hprt & 1.054 & & \\
Ywhaz & 0.949 & & \\
Ppia & 1.450 & $1.13-1.87$ & 0.004 up \\
Arhgap12 & 1.675 & $1.29-2.24$ & 0.006 up \\
Rgs5 & 2.562 & $1.27-4.81$ & 0.009 up \\
Pdgfra & 1.568 & $1.09-2.55$ & 0.026 up \\
Taf12 & 1.458 & $0.93-2.23$ & 0.052 \\
Fgf18 & 1.716 & $0.92-2.81$ & 0.054 \\
Agtrap & 5.125 & $0.73-20.88$ & 0.062 \\
\hline
\end{tabular}

Relative expression ratios, standard error, and statistical analysis were calculated by the relative expression software tool (RESTC Version 2.07). An upregulation indicates an elevated amount of mRNA in the $\mathrm{Crem}^{-1-}$ VSMCs $(n=5)$

particularly important for the regulation of proliferation, suggesting an important role of Crem in vasculoproliferative diseases.

To evaluate the functionality of the inactivation of Crem in VSMCs and to exclude possible compensatory effects of other transcription factors acting at CREs, we analyzed the CREmediated transcriptional activity in response to Forskolin to stimulate the cAMP-dependent signaling cascade. Such compensatory effects were previously observed in different genetic mouse models $[3,13,9]$. For experiments, isolated VSMCs of low passages $(<2)$ and high purity over $95 \%$ of Myh11positive cells were used to minimize effects of phenotypic modulation [5] and contamination of other cell types, e.g., endothelial cells. Crem inactivation in VSMCs increased CRE-mediated transcriptional activity, likely as a consequence of a derepressed activity of CREB or other activating transcription factors like activating transcription factor 1

Table 2 Expression analysis of selected genes in the aorta of $\mathrm{Crem}^{-/-}$ and $\mathrm{Crem}^{+/+}$mice by quantitative real-time PCR

\begin{tabular}{llll}
\hline Gene & Relative expression & Standard error & $p$ value \\
\hline Hprt & 1.000 & & \\
Ppia & 1.102 & $0.74-1.67$ & 0.454 \\
Arhgap12 & 1.049 & $0.42-2.50$ & 0.858 \\
Rgs5 & 1.909 & $0.87-4.11$ & 0.011 up \\
Pdgfra & 0.984 & $0.52-1.85$ & 0.934 \\
Taf12 & 0.945 & $0.53-1.76$ & 0.779 \\
Fgf18 & 0.801 & $0.44-1.51$ & 0.245 \\
Agtrap & 1.043 & $0.43-2.45$ & 0.875 \\
\hline
\end{tabular}

Relative expression ratios, standard error, and statistical analysis were calculated by the relative expression software tool (RESTC Version 2.07). An upregulation indicates an elevated amount of mRNA in the $\mathrm{Crem}^{-/-}$aortae $(n=11-12)$
(ATF1). Therefore, Crem isoforms appear to have predominantly inhibitory functions in VSMCs and the increase in CRE-mediated gene expression underscores the functionality of the Crem inactivation and excludes the possibility that a lacking vascular phenotype of $\mathrm{Crem}^{-/-}$mice under basal conditions is due to a full compensation within the $\mathrm{Creb} /$ Crem family of transcription factors. Besides, the cAMPdependent signaling $\mathrm{NO}$ and the soluble guanylate cyclase/ cGMP signaling cascade have been suggested to phosphorylate $\mathrm{Creb}$ either by activation of mitogen-activated kinases or by direct phosphorylation of Creb (for review, see [31]). Steinbicker et al. reported that treatment of rat pulmonary artery cells with the NO donor $S$-nitroso-glutathione induced the Crem isoform Icer by activated CRE-mediated gene expression [40]. These results suggest that NO is a potent regulator of CRE-mediated gene expression. However, using the NO donor SNAP or a cGMP analogon, we did not find an induction or differences of CRE-mediated gene expression in the primary aortic VSMCs, indicating a minor role of NO for CRE-dependent gene expression in murine aortic VSMCs under our experimental conditions. However, stimulation of VSMCs with Pdgf revealed an increase of CRE-mediated gene expression in the $\mathrm{Crem}^{-/}$VSMCs which was completely blunted in the $\mathrm{Crem}^{+/+}$cells. This indicates that the stimulation with Pdgf activates CRE-mediated gene expression, but this mechanism is controlled by Crem.

Since cAMP-dependent CRE-mediated gene expression was already increased in $\mathrm{Crem}^{-/-}$aortic VSMCs under basal physiological conditions, we first studied the impact of Crem inactivation on aortic contractility, VSMC proliferation, apoptosis, and morphological abnormalities with regard to possible physiological changes. Previous findings by catheterization of the left ventricle showed that $\mathrm{Crem}^{-/}$mice exhibit a lower left-ventricular blood pressure than $\mathrm{Crem}^{+/+}$animals [27], which could be associated with alterations in the contractility of the vascular system. Moreover, a loss of the Creb isoforms $\alpha$ and $\Delta$ was linked to a higher pulmonary vascular resistance [23]. Our analysis revealed that neither the PE- or prostaglandin-mediated vasoconstriction nor the $\beta$-adrenergic, muscarinic, or NO-dependent vasorelaxation was different concerning the maximal effects or the $\mathrm{EC}_{50} / \mathrm{IC}_{50}$ in $\mathrm{Crem}^{-1}$ - mice versus $\mathrm{Crem}^{+/+}$mice. Furthermore, no differences in contractility of $\mathrm{Crem}^{-/-}$mice versus $\mathrm{Crem}^{+/+}$mice could be detected in endothelium-denuded aortae and in aortae of 1 week isoproterenol-treated animals. Consequently, our data indicate that Crem-derived transcription factors do not play an important role in the regulation of proteins responsible for the regulation of the aortic contractility, on the one hand, in both VSMCs and endothelial cells and, on the other hand, under basal and catecholamine-induced stress conditions reflected by the isoproterenol-treated animals. Detailed morphological and immunohistochemical analysis did not show any differences in the macroscopic appearance, media thickness, 
proliferative activity, and apoptotic rate of VSMCs in aortic sections. Although these experiments only showed the condition in the adult animal, one can deduce that Crem also is not essential for development in general and especially in the formation of the contractile apparatus during mouse embryogenesis. Taken together, the basal increase in CRE-mediated gene expression in $\mathrm{Crem}^{-/}$mice particularly had no effect on the physiology of the vasculature and the quiescence of VSMCs.

Stimulation of VSMCs with Pdgf revealed an increase of CRE-mediated gene expression in the $\mathrm{Crem}^{-/}$VSMCs which was completely blunted in the $\mathrm{Crem}^{+/+}$cells. This indicates that Crem is able to completely suppress the Pdgf-dependent CRE-mediated gene expression. Hence, conditions of elevated Pdgf release should generate an increased CRE-mediated gene expression in VSMCs with possible consequences for cellular physiology. We tested this hypothesis in vivo in the pathophysiological models of atherosclerotic plaque development in Crem $\times \mathrm{ApoE}^{-/-}$mice and the ligation of the carotid artery, which are associated with increased Pdgf production $[47,34,6]$. Despite $\mathrm{Crem}^{-/} \times \mathrm{ApoE}^{-/-}$mice showing a slight increase of plaque burden after 30 weeks of high-fat diet, a detailed analysis of plague development revealed no differences between $\mathrm{Crem}^{-/-} \times \mathrm{ApoE}^{-/-}$and $\mathrm{Crem}^{+/+} \times \mathrm{ApoE}^{-/-}$ mice. Ligation of the carotid artery in $\mathrm{Crem}^{+/+}$mice was associated with a marked downregulation of Crem mRNA levels, supporting the relevance of Crem in this context. Accordingly, the complete inactivation of Crem led to a severe increase of neointima formation in the $\mathrm{Crem}^{-/-}$mice associated with an increased proliferation rate of VSMCs in the media. This corroborates to results of Herring et al. showing that the majority of neointima-forming cells are derived from differentiated medial smooth muscle cells [12]. Although endothelium-mediated effects could not be excluded in this context, levels of Icam and Vcam reflecting endothelium activation via inflammatory mediators [43] showed no differences between the genotypes. Primary VSMCs of $\mathrm{Crem}^{-/}$ mice exhibited a higher amount of proliferative cells after stimulation with Pdgf. Therefore, the increased neointima formation could be explained mainly by the elevated capacity of $\mathrm{Crem}^{-/-}$VSMCs to proliferate. These findings fit well with results in rats suggesting that an adenoviral expression of the Crem isoform Icer inhibits VSMC proliferation and at least contributes to the effects of Crem in vasculature [28].

In primary Pdgf-stimulated $\mathrm{Crem}^{-/}$VSMCs, we found an upregulation of the Pdgf receptor, alpha polypeptide (Pdgfra) compared to $\mathrm{Crem}^{+/+}$controls. Pdgf signaling via Pdgf receptors (Pdgfrs) plays an important role in the formation of the neointima after vascular injury, and administration of a Pdgfra antibody reduces neointima development in an allograft model in rats [34, 24]. Furthermore, Pdgfra levels increase during aging associated with an increase of proliferative response and increased neointima formation after wire injury [45]. Watson et al. showed that Pdgfra levels were inversely regulated to the Creb content in SMCs [46]. Since short Crem isoforms, acting as transcriptional repressors, can be rapidly induced via activated Creb/CRE-mediated signaling cascades [26, 38], Pdgfra content could be inversely regulated via an activator (Creb)induced inhibitor (Crem) regulatory loop.

Moreover, cyclophilin A (Ppia) mRNA was increased in $\mathrm{Crem}^{-/-}$VSMCs and is therefore associated with a higher proliferation rate. Since Ppia is a possible target gene of Creb [48], it might be activated by the inactivation of the repressor Crem. Ppia overexpression in VSMCs increases neointima formation and is involved in VSMC migration and proliferation as well as inflammatory cell accumulation [36], corroborating with our observations. Interestingly, we observed an upregulation of the regulator of G-protein signaling $5\left(R g_{s} 5\right)$ mRNA. The regulator of G-protein signaling 5 is a highly and differentially expressed member of the G-protein signaling ( $\mathrm{Rgs}$ ) proteins in the arterial smooth muscle. In a model of $\beta_{2}$-adrenoceptor overexpression or after isoproterenol treatment, Rgs5 is upregulated in atria [16]. This links the expression of Rgs5 to cAMPdependent signaling, and indeed, we found an upregulation of Rgs5 in the aortae of $\mathrm{Crem}^{-/-}$mice, which exhibit an increased cAMP-dependent gene expression. The role of Rgs5 in the vasculature is not understood in detail so far. Rgs5 is downregulated under Pdgf stimulation, and this downregulation was linked to an overall activation of smooth muscle cells associated with an activation of $\mathrm{G}_{\mathrm{q} \alpha} / \mathrm{G}_{\mathrm{i} \alpha}$ signaling, increased migration, hypertrophic response, and vascular remodeling [10]. Cho et al. showed that Rgs5 is upregulated during maturation and acts as a potent GTPase of $\mathrm{G}_{\mathrm{q} \alpha} / \mathrm{G}_{\mathrm{i} \alpha}$ signaling [4]. Arnold et al. reported an increased abundance of Rgs5 in growing collateral arterioles during arteriogenesis and a $70 \%$ decreased neointima formation in Rgs5-deficient mice. They suggested that Rgs5 shifts $\mathrm{G}_{\alpha \mathrm{q} / 11}$ signaling towards a $\mathrm{G}_{\alpha 12 / 13}$-mediated Rho kinase-dependent SMC activation [1] and Rho kinase inhibition was found to decrease neointima formation [39]. However, the specific roles of, e.g., Rgs5, Pdgfra, and Ppia and their possible mutual interdependencies need further evaluation.

In conclusion, $\mathrm{Crem}^{-/}$mice represent a valuable genetic mouse model to study the functional consequences of increased CRE-mediated transcriptional activation in vasculature. Crem is a potent repressor of Pdgf-CRE-mediated signaling associated with inhibition of proliferation in VSMCs. Moreover, our experiments show that Crem is an important regulator of gene expression under pathophysiological conditions, associated with increased Pdgf release, like vascular injury.

Acknowledgments We thank Marianne Jansen-Rust, Danuta Mitko, Maria Schulik, Melanie Voß, and Andrea Walter for excellent technical assistance.

Sources of funding This study was funded by the Interdisciplinary Center of Clinical Research, Münster (IZKF, Mü1/004/07 to F.U.M. 
and W.S.), and the Deutsche Forschungsgemeinschaft (DFG Mu1376/111 to F.U.M. and W.S.).

Disclosures None

Open Access This article is distributed under the terms of the Creative Commons Attribution License which permits any use, distribution, and reproduction in any medium, provided the original author(s) and the source are credited.

\section{References}

1. Arnold C, Feldner A, Pfisterer L, Hodebeck M, Troidl K, Genove G, Wieland T, Hecker M, Korff T (2014) RGS5 promotes arterial growth during arteriogenesis. EMBO Mol Med 6(8):1075-1089. doi:10. 15252/emmm.201403864

2. Begum N, Hockman S, Manganiello VC (2011) Phosphodiesterase 3A (PDE3A) deletion suppresses proliferation of cultured murine vascular smooth muscle cells (VSMCs) via inhibition of mitogenactivated protein kinase (MAPK) signaling and alterations in critical cell cycle regulatory proteins. J Biol Chem 286(29):26238-26249. doi:10.1074/jbc.M110.214155

3. Blendy JA, Kaestner KH, Weinbauer GF, Nieschlag E, Schutz G (1996) Severe impairment of spermatogenesis in mice lacking the CREM gene. Nature 380(6570):162-165. doi:10.1038/380162a0

4. Cho H, Kozasa T, Bondjers C, Betsholtz C, Kehrl JH (2003) Pericytespecific expression of Rgs5: implications for PDGF and EDG receptor signaling during vascular maturation. FASEB J: Off Publ Fed Am Soc Exp Biol 17(3):440-442. doi:10.1096/fj.02-0340fje

5. Clempus RE, Sorescu D, Dikalova AE, Pounkova L, Jo P, Sorescu GP, Schmidt HH, Lassegue B, Griendling KK (2007) Nox4 is required for maintenance of the differentiated vascular smooth muscle cell phenotype. Arterioscler Thromb Vasc Biol 27(1):42-48. doi:10. 1161/01.ATV.0000251500.94478.18

6. Ferns GA, Raines EW, Sprugel KH, Motani AS, Reidy MA, Ross R (1991) Inhibition of neointimal smooth muscle accumulation after angioplasty by an antibody to PDGF. Science 253(5024):1129-1132, PMID: 1653454

7. Fujimoto T, Fujisawa J, Yoshida M (1994) Novel isoforms of human cyclic AMP-responsive element modulator (hCREM) mRNA. J Biochem 115(2):298-303, PMID:8206879

8. Funakoshi Y, Ichiki T, Takeda K, Tokuno T, Iino N, Takeshita A (2002) Critical role of cAMP-response element-binding protein for angiotensin II-induced hypertrophy of vascular smooth muscle cells. J Biol Chem 277(21):18710-18717. doi:10.1074/jbc.M110430200

9. Groussin L, Massias JF, Bertagna X, Bertherat J (2000) Loss of expression of the ubiquitous transcription factor cAMP response element-binding protein (CREB) and compensatory overexpression of the activator CREMtau in the human adrenocortical cancer cell line H295R. J Clin Endocrinol Metab 85(1):345-354. doi:10.1210/ jcem.85.1.6307

10. Gunaje JJ, Bahrami AJ, Schwartz SM, Daum G, Mahoney WM Jr (2011) PDGF-dependent regulation of regulator of $G$ protein signaling-5 expression and vascular smooth muscle cell functionality. Am J Physiol Cell Physiol 301(2):C478-C489. doi:10.1152/ajpcell. 00348.2010

11. Hayashi S, Morishita R, Matsushita H, Nakagami H, Taniyama Y, Nakamura T, Aoki M, Yamamoto K, Higaki J, Ogihara T (2000) Cyclic AMP inhibited proliferation of human aortic vascular smooth muscle cells, accompanied by induction of p53 and p21. Hypertension 35(1 Pt 2):237-243, PMID:10642304
12. Herring BP, Hoggatt AM, Burlak C, Offermanns S (2014) Previously differentiated medial vascular smooth muscle cells contribute to neointima formation following vascular injury. Vasc Cell 6:21. doi: 10.1186/2045-824X-6-21

13. Hummler E, Cole TJ, Blendy JA, Ganss R, Aguzzi A, Schmid W, Beermann F, Schutz G (1994) Targeted mutation of the Creb genecompensation within the Creb/Atf family of transcription factors. Proc Natl Acad Sci U S A 91(12):5647-5651. doi:10.1073/pnas.91. 12.5647

14. Ichiki T (2006) Role of cAMP response element binding protein in cardiovascular remodeling: good, bad, or both? Arterioscler Thromb Vasc Biol 26(3):449-455. doi:10.1161/01.ATV.0000196747.79349.d1

15. Jalvy S, Renault MA, Lam Shang Leen L, Belloc I, Reynaud A, Gadeau AP, Desgranges C (2007) CREB mediates UTP-directed arterial smooth muscle cell migration and expression of the chemotactic protein osteopontin via its interaction with activator protein-1 sites. Circ Res 100(9):1292-1299. doi:10.1161/01.RES. 0000266609.28312.de

16. Jean-Baptiste G, Li X, Yang Z, Heubach J, Gaudio S, Khoury C, Ravens U, Greenwood MT (2005) Beta adrenergic receptor-mediated atrial specific up-regulation of RGS5. Life Sci 76(13):1533-1545. doi:10.1016/j.lfs.2004.11.001

17. Johannessen M, Delghandi MP, Moens U (2004) What turns CREB on? Cell Signal 16(11):1211-1227. doi:10.1016/j.cellsig.2004.05.001

18. Klemm DJ, Watson PA, Frid MG, Dempsey EC, Schaack J, Colton LA, Nesterova A, Stenmark KR, Reusch JE (2001) cAMP response element-binding protein content is a molecular determinant of smooth muscle cell proliferation and migration. J Biol Chem 276(49):46132-46141. doi:10.1074/jbc.M104769200

19. Knapp J, Aleth S, Balzer F, Gergs U, Schmitz W, Neumann J (2006) Comparison of contractile responses in isolated mouse aorta and pulmonary artery: influence of strain and sex. J Cardiovasc Pharmacol 48(1):820-826. doi:10.1097/01.fjc.0000232062.80084.4f

20. Kumar A, Hoover JL, Simmons CA, Lindner V, Shebuski RJ (1997) Remodeling and neointimal formation in the carotid artery of normal and P-selectin-deficient mice. Circulation 96(12):4333-4342. doi:10. 1161/01.CIR.96.12.4333

21. Kumar A, Lindner V (1997) Remodeling with neointima formation in the mouse carotid artery after cessation of blood flow. Arterioscler Thromb Vasc Biol 17(10):2238-2244. doi:10.1161/01.ATV.17.10. 2238

22. Leopold JA, Dam A, Maron BA, Scribner AW, Liao R, Handy DE, Stanton RC, Pitt B, Loscalzo J (2007) Aldosterone impairs vascular reactivity by decreasing glucose-6-phosphate dehydrogenase activity. Nat Med 13(2):189-197. doi:10.1038/nm1545

23. Li L, Howell K, Sands M, Banahan M, Frohlich S, Rowan SC, Neary R, Ryan D, McLoughlin P (2013) The alpha and delta isoforms of CREB1 are required to maintain normal pulmonary vascular resistance. PLoS One 8(12):e80637. doi:10.1371/journal.pone.0080637

24. Mancini MC, Evans JT (2000) Role of platelet-derived growth factor in allograft vasculopathy. Ann Surg 231(5):682-688, PMID:1421055

25. Mayr B, Montminy M (2001) Transcriptional regulation by the phosphorylation-dependent factor CREB. Nat Rev Mol Cell Biol 2(8):599-609. doi:10.1038/35085068

26. Molina CA, Foulkes NS, Lalli E, Sassone-Corsi P (1993) Inducibility and negative autoregulation of CREM: an alternative promoter directs the expression of ICER, an early response repressor. Cell 75(5): 875-886, PMID:8252624

27. Muller FU, Lewin G, Matus M, Neumann J, Riemann B, Wistuba J, Schutz G, Schmitz W (2003) Impaired cardiac contraction and relaxation and decreased expression of sarcoplasmic Ca2+-ATPase in mice lacking the CREM gene. FASEB J: Off Publ Fed Am Soc Exp Biol 17(1):103-105. doi:10.1096/fj.02-0486fje

28. Ohtsubo $\mathrm{H}$, Ichiki $\mathrm{T}$, Miyazaki $\mathrm{R}$, Inanaga $\mathrm{K}$, Imayama I, Hashiguchi Y, Sadoshima J, Sunagawa K (2007) Inducible cAMP early repressor inhibits growth of vascular smooth 
muscle cell. Arterioscler Thromb Vasc Biol 27(7):1549-1555. doi:10.1161/ATVBAHA.107.145011

29. Ono H, Ichiki T, Fukuyama K, Iino N, Masuda S, Egashira K, Takeshita A (2004) cAMP-response element-binding protein mediates tumor necrosis factor-alpha-induced vascular smooth muscle cell migration. Arterioscler Thromb Vasc Biol 24(9):1634-1639. doi:10. 1161/01.ATV.0000138052.86051.0d

30. Pfaffl MW, Horgan GW, Dempfle L (2002) Relative expression software tool (REST) for group-wise comparison and statistical analysis of relative expression results in real-time PCR. Nucleic Acids Res 30(9):e36, PMID:113859

31. Pilz RB, Broderick KE (2005) Role of cyclic GMP in gene regulation. Front Biosci: J Virtual Libr 10:1239-1268, PMID:15769622

32. Pilz RB, Casteel DE (2003) Regulation of gene expression by cyclic GMP. Circ Res 93(11):1034-1046. doi:10.1161/01.RES. 0000103311.52853 .48

33. Quinn PG (2002) Mechanisms of basal and kinase-inducible transcription activation by CREB. Prog Nucleic Acid Res Mol Biol 72: 269-305, PMID: 12206454

34. Raines EW (2004) PDGF and cardiovascular disease. Cytokine Growth Factor Rev 15(4):237-254. doi:10.1016/j.cytogfr.2004.03.004

35. Reusch JE, Watson PA (2004) Loss of CREB regulation of vascular smooth muscle cell quiescence in diabetes. Rev Endocr Metab Disord 5(3):209-219. doi:10.1023/B:REMD.0000032409.13963.bc

36. Satoh K, Matoba T, Suzuki J, O’Dell MR, Nigro P, Cui Z, Mohan A, Pan S, Li L, Jin ZG, Yan C, Abe J, Berk BC (2008) Cyclophilin A mediates vascular remodeling by promoting inflammation and vascular smooth muscle cell proliferation. Circulation 117(24):3088 3098. doi:10.1161/CIRCULATIONAHA.107.756106

37. Schauer IE, Knaub LA, Lloyd M, Watson PA, Gliwa C, Lewis KE, Chait A, Klemm DJ, Gunter JM, Bouchard R, McDonald TO, O’Brien $\mathrm{KD}$, Reusch JE (2010) CREB downregulation in vascular disease: a common response to cardiovascular risk. Arterioscler Thromb Vasc Biol 30(4):733-741. doi:10.1161/ATVBAHA.109.199133

38. Seidl MD, Nunes F, Fels B, Hildebrandt I, Schmitz W, Schulze-Osthoff $\mathrm{K}$, Muller FU (2014) A novel intronic promoter of the Crem gene induces small ICER (smICER) isoforms. FASEB J: Off Publ Fed Am Soc Exp Biol 28(1):143-152. doi:10.1096/fj.13-231977

39. Shibata R, Kai H, Seki Y, Kato S, Morimatsu M, Kaibuchi K, Imaizumi $\mathrm{T}$ (2001) Role of Rho-associated kinase in neointima formation after vascular injury. Circulation 103(2):284-289

40. Steinbicker AU, Liu H, Jiramongkolchai K, Malhotra R, Choe EY, Busch CJ, Graveline AR, Kao SM, Nagasaka Y, Ichinose F, Buys ES, Brouckaert P, Zapol WM, Bloch KD (2011) Nitric oxide regulates pulmonary vascular smooth muscle cell expression of the inducible cAMP early repressor gene. Nitric Oxide 25(3):294-302. doi:10. 1016/j.niox.2011.05.006

41. Tokunou T, Ichiki T, Takeda K, Funakoshi Y, Iino N, Shimokawa H, Egashira K, Takeshita A (2001) Thrombin induces interleukin-6 expression through the cAMP response element in vascular smooth muscle cells. Arterioscler Thromb Vasc Biol 21(11):1759-1763. doi: 10.1161/hq1101.098489

42. Tokunou T, Shibata R, Kai H, Ichiki T, Morisaki T, Fukuyama K, Ono H, Iino N, Masuda S, Shimokawa H, Egashira K, Imaizumi T, Takeshita A (2003) Apoptosis induced by inhibition of cyclic AMP response element-binding protein in vascular smooth muscle cells. Circulation 108(10):1246-1252. doi:10.1161/01.CIR.0000085164. 13439.89

43. van Buul JD, van Rijssel J, van Alphen FP, van Stalborch AM, Mul EP, Hordijk PL (2010) ICAM-1 clustering on endothelial cells recruits VCAM-1. J Biomed Biotechnol 2010:120328. doi:10.1155/ 2010/120328

44. Vandesompele J, De Preter K, Pattyn F, Poppe B, Van Roy N, De Paepe A, Speleman F (2002) Accurate normalization of real-time quantitative RT-PCR data by geometric averaging of multiple internal control genes. Genome Biol 3 (7):RESEARCH0034. PMID:126239

45. Vazquez-Padron RI, Lasko D, Li S, Louis L, Pestana IA, Pang M, Liotta C, Fornoni A, Aitouche A, Pham SM (2004) Aging exacerbates neointimal formation, and increases proliferation and reduces susceptibility to apoptosis of vascular smooth muscle cells in mice. J Vasc Surg 40(6):1199-1207. doi:10.1016/j.jvs.2004.08.034

46. Watson PA, Vinson C, Nesterova A, Reusch JE (2002) Content and activity of cAMP response element-binding protein regulate plateletderived growth factor receptor-alpha content in vascular smooth muscles. Endocrinology 143(8):2922-2929. doi:10.1210/endo.143. 8.8959

47. Wu CH, Chen YC, Hsiao G, Lin CH, Liu CM, Sheu JR (2001) Mechanisms involved in the inhibition of neointimal hyperplasia by abciximab in a rat model of balloon angioplasty. Thromb Res 101(3): $127-138$

48. Zhang X, Odom DT, Koo SH, Conkright MD, Canettieri G, Best J, Chen H, Jenner R, Herbolsheimer E, Jacobsen E, Kadam S, Ecker JR, Emerson B, Hogenesch JB, Unterman T, Young RA, Montminy M (2005) Genome-wide analysis of cAMP-response element binding protein occupancy, phosphorylation, and target gene activation in human tissues. Proc Natl Acad Sci U S A 102(12):4459-4464. doi: 10.1073/pnas.0501076102 